\title{
PEDIATRICS
}

\section{Regional Variation in Survival of People With Cerebral Palsy in the United Kingdom}

Karla Hemming, Jane L. Hutton, Allan Colver and Mary-Jane Platt

Pediatrics 2005;116;1383-1390

DOI: 10.1542/peds.2005-0259

\section{This information is current as of December 6, 2005}

The online version of this article, along with updated information and services, is located on the World Wide Web at:

http://www.pediatrics.org/cgi/content/full/116/6/1383

PEDIATRICS is the official journal of the American Academy of Pediatrics. A monthly publication, it has been published continuously since 1948. PEDIATRICS is owned, published, and trademarked by the American Academy of Pediatrics, 141 Northwest Point Boulevard, Elk Grove Village, Illinois, 60007. Copyright @ 2005 by the American Academy of Pediatrics. All rights reserved. Print ISSN: 0031-4005. Online ISSN: 1098-4275.

\section{American Academy of Pediatrics}




\title{
Regional Variation in Survival of People With Cerebral Palsy in the United Kingdom
}

\author{
Karla Hemming, $\mathrm{PhD}^{*}$; Jane L. Hutton, $\mathrm{PhD}^{*}$; Allan Colver, MD ; and \\ Mary-Jane Platt, MBBS, MPH, MRCGP, MFPHM§
}

\begin{abstract}
Objectives. Regional variation in survival of people who have cerebral palsy (CP) has been observed but not previously investigated in detail. In addition to true differences, variations in the methods and definitions used, completeness of ascertainment, and the role of potential confounding factors all have been proposed as possible explanations for these observed variations. Our aim was to assess the regional differences in survival of young people with $\mathrm{CP}$ and the effect on survival of socioeconomic differences after adjustment for variations in level of impairment and birth characteristics.
\end{abstract}

Methods. Survival patterns for young people with CP were calculated using information from a collaborative database. This database consisted of registrations of children who were born with CP in 5 geographically defined areas in the United Kingdom between 1980 and 1996. Notification of subsequent deaths was provided by the relevant births and death register. We consider the effects of birth characteristics, socioeconomic status, and severity of CP on survival.

Results. There were 325 deaths among the 4007 cases of CP identified. The proportion of affected children who survived to 20 years of age ranged from $85 \%$ (Mersey-side and Cheshire, male individuals) to $94 \%$ (North of England, male individuals). Multivariate modeling showed that the severity of impairment had the biggest impact on survival and that additional contributions were made by birth weight and socioeconomic status but that after such adjustments regional differences were no longer significant.

Conclusions. The number and the severity of impairments are the best predictors of survival in young people with CP. After adjustment for the number of impairments, children who were born in affluent areas and had a low birth weight have an increased risk for death over those who were born with a normal birth weight. The same does not hold, however, for those who were born in deprived areas. Pediatrics 2005;116:1383-1390; survival, impairments, birth weight, socioeconomic status.

From the *Department of Statistics, University of Warwick, Coventry, United Kingdom; $¥$ School of Clinical Medical Sciences, The University of Newcastle, Newcastle, United Kingdom; and §Department of Public Health, The University of Liverpool, Liverpool, United Kingdom.

Accepted for publication Apr 22, 2005.

doi:10.1542/peds.2005-0259

No conflict of interest declared.

Reprint requests to (J.L.H.) Department of Statistics, University of Warwick, Coventry, CV4 7AL, UK. E-mail: J.L.Hutton@warwick.ac.uk

PEDIATRICS (ISSN 0031 4005). Copyright (C) 2005 by the American Academy of Pediatrics.
ABBREVIATIONS. CP, cerebral palsy; UKCP, United Kingdom Collaborative Network of Cerebral Palsy Registers; CI, confidence interval.

$\mathrm{P}$ revious work has reported that most children with cerebral palsy (CP) survive to adulthood, unless they have severe motor and cognitive impairment. ${ }^{1-9}$ Some variations have been observed in reported survival rates from different regions and countries. However, much has been attributed to differences in severity profiles of the groups studied. Indeed, after conditioning on severity of impairment, country variations between California and Western Australia were no longer evident. ${ }^{10}$ In contrast, reported survival rates from England among the group with severe impairments do seem to differ. ${ }^{7}$ It is unclear from the published work whether these regional variations observed in England reflect true differences, for example, reflecting regional variations in general survival patterns, risk factor profiles, or levels of care, or rather are artifactual, for example, relating to differences in definition or measurement of impairments or differences in the ascertainment of those with the most severe impairment.

The United Kingdom Collaborative Network of Cerebral Palsy Registers (UKCP) brings together 5 research groups, each looking at the prevalence and the severity of $\mathrm{CP}$ among children who were born within separate, defined geographic areas in the United Kingdom. Issues of variations in ascertainment and in the definition and the measurement of impairments have been addressed. It therefore is possible to determine whether regional differences in survival are maintained after adjustments for variations in levels of impairment and birth characteristics. Furthermore, the effect of socioeconomic status on survival into adulthood for children who are severely affected by $\mathrm{CP}$ was investigated.

\section{METHODS}

\section{UKCP}

The 5 participating registers were the Merseyside and Cheshire Cerebral Palsy Register $2,9,11$; the North of England Collaborative Cerebral Palsy Survey ${ }^{7,12}$; the Northern Ireland Cerebral Palsy Register ${ }^{13}$; 4Child-the Four Counties Database of Cerebral Palsy, Vision Loss and Hearing Loss in Children ${ }^{14,15}$ (formerly the Oxford Register of Early Childhood Impairments); and the Scottish Register of Children with a Motor Deficit of Central Origin. ${ }^{14,16}$ Henceforth, the registers will be referred to as Mersey, North of England, Oxford, Northern Ireland, and Scotland, respectively. The geographic regions covered by these registers were for Mersey the counties of Cheshire and Merseyside; for the North of 
England the former health districts of Northumberland, Newcastle, and North Tyneside until 1990 and the former health Northern region after 1990; for Oxford the counties of Buckinghamshire, Berkshire, Northamptonshire, and Oxfordshire; and all of Northern Ireland and Scotland. Full details of assessment, ascertainment, and consent methods for each of the registers may be found in the references.

A collaborative database to which the 5 registers submitted anonymized details of their cases was established. Cases were defined as children with early-impairment $\mathrm{CP}$, that is $\mathrm{CP}$ that is believed to be attributable to an insult that occurred before age 28 days. Data on gender, birth weight, gestational age, year of birth, type and levels of impairments, and socioeconomic status were provided.

The 5 registers that contributed to the collaboration were established at different times, and the periods for which cases were available varies by register. Cases were included from year of birth 1980 for Mersey and the North of England and available from 1981 for Northern Ireland and 1984 for Oxford and Scotland. The North of England, Northern Ireland, and Oxford provided information on births up until 1996, whereas Mersey and Scotland had information on births until 1989. Cases from all 5 registers were followed up for death notifications until March 31, 2004. Each register flagged its cases with the relevant births and deaths register (the National Health Services Central Register for England and the Northern Ireland Central Services Agency or General Register Office for Scotland), which notifies the register when a flagged person dies. The U.K. system of death registration, in which by law all deaths must be registered, ensures that the fact of death is recorded for virtually all people. Dates of death for those who are abroad with the armed forces were also recorded, as were dates of emigration. Lifetimes were computed in weeks from birth until death. For those still alive, lifetimes in weeks from birth until the chosen censoring date, March 31, 2004 (or date of emigration), were computed. This censoring date had a lag of $\sim 3$ months to allow for any delays in notifications of deaths.

Our inclusion criteria were that cases had to be flagged with the relevant births and deaths register, alive at age 2 years, and born to a mother who was known to be resident within the defined geographic regions of the registers. Inclusion of only those cases that were flagged successfully ensured that all deaths and emigrations were reported, and inclusion of only those infants who were alive at age 2 years recognizes that children who have $C P$ and die before age 2 years are underreported ${ }^{17}$.

\section{Classification of Covariates}

Gestational age was classified into 2 groups: preterm $(<37$ weeks) and term infants ( $\geq 37$ weeks). For birth weight, 2 classification groups were used: low birth weight $(<2500 \mathrm{~g})$ and normal birth weight $\left(\geq 2500 \mathrm{~g}\right.$ ). The Carstairs index of deprivation ${ }^{18}$ was used as a measure of socioeconomic status, using ward of residence of the mother at the time of the birth, and standardized to the U.K. population. Quintiles range from 1, the most affluent, to 5 , the most deprived, and the dichotomy "deprived" (Carstairs 4 and 5) and "affluent" (Carstairs 1, 2, and 3) was used here.

The binary categories "severe" and "not severe" were used to classify impairment variables. For lower limb function, a severe impairment indicates that the child is unable to walk even with aids, uses a wheelchair, or is bedridden. For upper limb function, a severe impairment indicates that the child is unable to feed or self-dress. A severe visual impairment is defined as vision in the better eye $<6 / 60$. A severe hearing impairment is defined as a hearing loss in the better ear $>70$ decibels averaged across frequencies 0.5 to $4 \mathrm{kHz}$. A severe intellectual impairment is defined as an IQ $<50$. For the sensory and cognitive variables, assessment of impairments was made by formal testing procedures or by clinical judgment when formal testing was not possible.

\section{Statistical Analyses}

Kaplan-Meier survival estimates at ages 5 to 20 years (where data permit) by 5 -year intervals were provided for each region and decade of birth for male and female individuals. Numbers of cases in each group at the beginning of follow-up and standard error at 20 years (or last year of follow-up) were also provided. Regional variations by selected birth characteristics, impairments, and severity (except hearing, for which there are insufficient deaths in those with severe impairment to make any reasonable
TABLE 1. Demographic Characteristics of Children With CP by the 5 Regions

\begin{tabular}{lccccc}
\hline & Mersey & $\begin{array}{c}\text { North } \\
\text { England }\end{array}$ & $\begin{array}{c}\text { North } \\
\text { Ireland }\end{array}$ & Oxford & Scotland \\
\hline $\begin{array}{l}\text { Notifications } \\
\text { Cases }\end{array}$ & 768 & 745 & 885 & 955 & 654 \\
$\quad \begin{array}{l}\text { Deaths } \\
\text { Decade of birth }\end{array}$ & 90 & 54 & 67 & 63 & 51 \\
$\quad$ 1980s & 768 & 198 & 550 & 494 & 654 \\
$\quad$ 1990s & & 547 & 335 & 461 & \\
Gender & & & & & \\
$\quad$ Male & 428 & 459 & 485 & 554 & 375 \\
$\quad$ Female & 340 & 286 & 400 & 401 & 279 \\
$\quad$ M:F ratio & 1.3 & 1.6 & 1.2 & 1.4 & 1.3 \\
\hline
\end{tabular}

evaluations) were evaluated at 10 and 20 years. Differences between groups were evaluated using the log-rank test. ${ }^{19}$ Cox proportional hazards models ${ }^{19}$ were used to evaluate regional variations after adjustment for impairments, birth characteristics, socioeconomic status, and year of birth. Assumptions of proportionality were assessed by the Grambsch and Therneau methods, and best fits were evaluated using Akaike's information criterion. ${ }^{20}$

Expected survival proportions for the U.K. population, matched to the $\mathrm{CP}$ cohort by gender, year of birth, and alive at age 2 years, permitted comparisons with the general population. Expected survival estimates were computed using the relative survival package surv $2^{21}$ and using U.K. life tables (source: Government Actuary's Department).

\section{RESULTS}

Among the 4007 children who had early-impairment $\mathrm{CP}$, whose mother was resident in the defined regions at the time of the birth, who were flagged with the relevant births and deaths register, and who were alive at age 2 years, 325 deaths were reported (Table 1). There were more male than female individuals with $\mathrm{CP}$ across all the regions. The ratio of male to female individuals varied from 1.2 (Northern Ireland) to 1.6 (North of England), although these were not significantly different.

In general, more children were born at term and with normal birth weight in all regions than were born preterm or with low birth weight (Table 2). Proportions in the low birth weight group varied between 43\% (North of England, 1990s) and 51\% (Scotland, 1980s). A similar pattern was seen in the preterm births, which ranged from 39\% (the North of

TABLE 2. Secular and Regional Variations in Percentages of Children Who Were Born With Low Birth Weight, Preterm, and in Deprived Areas

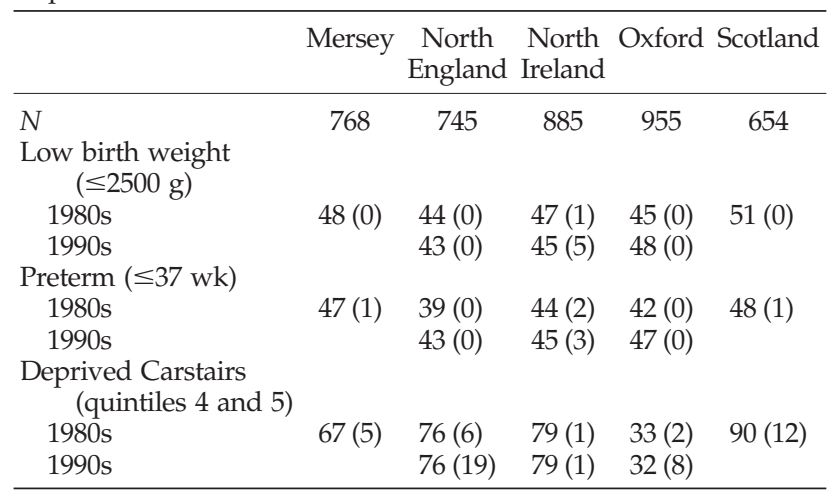

Percentages of cases for which the information on this variable is missing are in parentheses. 
TABLE 3. Secular and Regional Variations in Percentages of Children With Severe Impairment

\begin{tabular}{lccccc}
\hline & Mersey & $\begin{array}{c}\text { North } \\
\text { England }\end{array}$ & $\begin{array}{c}\text { North } \\
\text { Ireland }\end{array}$ & Oxford & Scotland \\
\hline$N \quad$ & 768 & 745 & 885 & 955 & 654 \\
$\begin{array}{l}\text { Severe lower limb } \\
\text { impairment }\end{array}$ & & & & & \\
$\quad$ 1980s & $27(0)$ & $30(9)$ & $30(3)$ & $33(1)$ & $36(4)$ \\
1990s & & $27(3)$ & $23(7)$ & $33(4)$ & \\
$\begin{array}{l}\text { Severe upper limb } \\
\text { impairment }\end{array}$ & & & & & \\
1980s & $22(0)$ & $25(6)$ & $22(5)$ & $22(2)$ & $25(4)$ \\
1990s & & $25(3)$ & $16(12)$ & $20(3)$ & \\
$\begin{array}{l}\text { Severe intellectual } \\
\text { impairment }\end{array}$ & & & & & \\
1980s & $30(1)$ & $25(5)$ & $33(8)$ & $30(13)$ & $3(63)$ \\
1990s & & $24(3)$ & $22(14)$ & $21(17)$ & \\
$\begin{array}{l}\text { Severe visual } \\
\text { impairment }\end{array}$ & & & & & \\
1980s & $11(9)$ & $5(11)$ & $11(9)$ & $13(7)$ & $18(41)$ \\
1990s & & $6(4)$ & $9(8)$ & $10(7)$ & \\
$\begin{array}{l}\text { Severe hearing } \\
\text { impairment }\end{array}$ & & & & & \\
$\begin{array}{l}\text { 1980s } \\
\text { 1990s }\end{array}$ & $2(1)$ & $3(9)$ & $2(8)$ & $2(10)$ & $2(9)$ \\
\hline
\end{tabular}

Percentages of cases for which the information on this variable is missing are in parentheses.

England, 1980s) to $48 \%$ (Scotland, 1980s). The majority of the children were born in deprived areas in all regions except Oxford, where just 33\% were. In Scotland, at the other extreme, $>90 \%$ of the children were born in deprived areas. The proportion of cases with missing information on gestational age and birth weight was very low in all regions $(<5 \%)$. Proportions of cases with missing information on socioeconomic status were higher $(\mathrm{eg}, 19 \%$ in the North of England in the 1990s).

Some variation was observed between the regions in the proportion of children with severe impairment (Table 3). For example, proportions of children with a severe lower limb impairment varied from $27 \%$ in Mersey to 36\% in Scotland in the 1980s; proportions with a severe intellectual impairment varied from $25 \%$ in the North of England to 30\% in the other regions in the 1980s (omitting Scotland because 63\% of data were missing). Rates of missing data were generally greater for the sensory variables (at $\sim 10 \%$ ) than motor variables (at $\sim 5 \%$ ) and were the highest and most variable for the intellectual impairment variable (as much as 63\% in Scotland but as little as $1 \%$ in Mersey). In Oxford and Northern Ireland, the proportion of cases with missing information on intellectual impairment increased in the 1990s. The rate of missing data from the North of England was lower in the 1990s than in the 1980s.

\section{Survival From Age Two Years}

The proportion of children who were alive at age 2 years and who survived to 20 years of age varied between 85\% (Mersey) and 94\% (North of England) for male individuals and between $87 \%$ (Mersey and the North of England) and 90\% (Northern Ireland and Oxford) for female individuals (Table 4). No significant variations in these survival proportions were detected. No significant differences were observed between the genders, either within regions or across all regions combined. For comparison and on the basis of the U.K. life tables matched to the UKCP cohort by year of birth and gender and alive at age 2 years, the 20-year survival rate in the general population was $99.2 \%$ for male individuals and $99.6 \%$ for female individuals.

In the 1980s, survival of children who were born preterm was significantly better $(P<.01)$ than those who were born at term; similarly, survival for those who were born with low birth weight was better than for those who were born with normal birth weight $(P<.01)$, across all regions (Table 5$)$. There was a significant regional variation for infants who were born preterm $(P<.01)$ or with low birth weight $(P<.01)$, with Mersey having the poorer outlook and the North of England and Scotland faring better. No significant regional variation was observed for children who were born at term or with a normal birth weight. Considering all children who were born in deprived areas, there was a significant regional variation in survival $(P<.1)$, with Mersey having a poorer outlook. There was a trend, although not significant, for affected children who were born in the more affluent areas to have better survival. In contrast, in Oxford, better survival was observed in the children from the less affluent areas.

For children with a particular impairment recorded as severe, those who were born in Mersey had a poorer outlook, whereas those who were born

TABLE 4. Survival of Those Who Were Alive at Age Two Years by Region and Decade: Percentages Surviving to Ages 5, 10, 15, and 20 Years

\begin{tabular}{|c|c|c|c|c|c|c|c|c|c|c|c|c|}
\hline & \multicolumn{6}{|c|}{ Male } & \multicolumn{6}{|c|}{ Female } \\
\hline & $5 \mathrm{y}$ & $10 \mathrm{y}$ & $15 \mathrm{y}$ & $20 \mathrm{y}$ & $n$ & SE & $5 \mathrm{y}$ & $10 \mathrm{y}$ & $15 \mathrm{y}$ & $20 \mathrm{y}$ & $n$ & SE \\
\hline \multicolumn{13}{|l|}{$1980 \mathrm{~s}$} \\
\hline Mersey & 97 & 93 & 90 & 85 & 428 & 1.8 & 96 & 94 & 92 & 87 & 340 & 1.8 \\
\hline North England & 99 & 98 & 95 & 94 & 123 & 2.0 & 97 & 93 & 91 & 87 & 75 & 3.3 \\
\hline North Ireland & 96 & 95 & 93 & 87 & 296 & 2.7 & 98 & 96 & 93 & 90 & 254 & 2.3 \\
\hline Oxford & 98 & 94 & 91 & 89 & 285 & 2.5 & 96 & 93 & 90 & 90 & 209 & 2.0 \\
\hline Scotland & 99 & 96 & 94 & 93 & 375 & 1.7 & 99 & 96 & 93 & 88 & 279 & 1.7 \\
\hline \multicolumn{13}{|l|}{$1990 \mathrm{~s}$} \\
\hline North England & 97 & 93 & & & 336 & 1.6 & 98 & 94 & & & 211 & 1.6 \\
\hline North Ireland & 98 & 96 & & & 189 & 2.3 & 99 & 97 & & & 146 & 2.1 \\
\hline Oxford & 98 & 97 & & & 266 & 1.6 & 99 & 98 & & & 192 & 1.8 \\
\hline
\end{tabular}

$n$ indicates number of cases at beginning of follow-up; SE, standard error at last year of follow-up. 
TABLE 5. Survival of Those Who Were Alive at Age Two Years by Selected Birth Characteristics in the 1980s: Percentages Surviving to Ages 10 and 20 Years

\begin{tabular}{|c|c|c|c|c|c|c|c|c|}
\hline & $10 \mathrm{y}$ & $20 \mathrm{y}$ & $n$ & SE & $10 \mathrm{y}$ & $20 \mathrm{y}$ & $n$ & SE \\
\hline & \multicolumn{4}{|c|}{ Normal birth weight $(2500 \mathrm{~g})$} & \multicolumn{4}{|c|}{ Low Birth Weight $(\leq 2500 \mathrm{~g})$} \\
\hline Mersey & 94 & 87 & 400 & 1.7 & 93 & 89 & 368 & 1.6 \\
\hline North England & 95 & 87 & 110 & 3.3 & 99 & 96 & 88 & 2.0 \\
\hline North Ireland & 95 & 87 & 286 & 2.2 & 95 & 91 & 257 & 1.9 \\
\hline Oxford & 92 & 87 & 269 & 2.1 & 97 & 92 & 225 & 2.4 \\
\hline \multirow[t]{2}{*}{ Scotland } & 93 & 87 & 317 & 2.1 & 98 & 95 & 334 & 2.7 \\
\hline & \multicolumn{4}{|c|}{ Term births (37 wk) } & \multicolumn{4}{|c|}{ Preterm ( $\leq 37 \mathrm{wk})$} \\
\hline Mersey & 93 & 86 & 408 & 1.8 & 94 & 90 & 355 & 1.7 \\
\hline North England & 95 & 88 & 120 & 3.1 & 99 & 97 & 78 & 1.8 \\
\hline North Ireland & 94 & 87 & 299 & 2.3 & 96 & 91 & 238 & 2.0 \\
\hline Oxford & 91 & 86 & 286 & 2.3 & 99 & 95 & 311 & 2.6 \\
\hline \multirow[t]{2}{*}{ Scotland } & 93 & 87 & 337 & 2.1 & 99 & 95 & 311 & 2.6 \\
\hline & \multicolumn{4}{|c|}{ Affluent (quintiles 1 to 3 ) } & \multicolumn{4}{|c|}{ Deprived (quintiles 4 and 5) } \\
\hline Mersey & 95 & 92 & 242 & 1.8 & 92 & 86 & 490 & 1.8 \\
\hline North England & 96 & 91 & 45 & 4.2 & 97 & 92 & 142 & 2.5 \\
\hline North Ireland & 96 & 90 & 112 & 3.1 & 95 & 88 & 434 & 2.5 \\
\hline Oxford & 93 & 89 & 324 & 1.8 & 95 & 92 & 160 & 2.2 \\
\hline Scotland & 96 & 96 & 56 & 2.5 & 95 & 90 & 522 & 1.9 \\
\hline
\end{tabular}

$n$ indicates number of cases at beginning of follow-up; SE, standard error at last year of follow-up.

in the North of England and Scotland had the best survival in the 1980s (Table 6). For example, in the North of England, for those with a severe lower limb impairment, $85 \%$ survived to 20 years of age, compared with just 58\% in Mersey. The IQ impairment variable showed the least disparity between regions and severe visual impairment the most. Significant differences $(P<.01)$ between the regions were detected for all impairment variables except for intellectual impairment. In the 1990s, of the 3 regions with data available (North of England, Northern Ireland, and Oxford), the North of England had the poorest outlook and Oxford the best for all severe impairment categories, although only significantly so $(P<.01)$ for those with a severe lower limb impairment. The 10-year survival in the Oxford area improved in the 1990s, compared with the 1980s $(P<$ $.05)$, whereas in the North of England, the opposite trend was seen (although not significant). There was no change in the 10-year survival in Northern Ireland during the 2 decades.

For each impairment, the survival for children without a severe impairment ranged from $97 \%$ to $99 \%$ at 20 years, with no significant temporal or regional variations; the exception was those with a nonsevere visual impairment in the North of England in the 1990s, who had a survival rate of $95 \%$ at 10 years, significantly lower than that in the other regions $(P<.01)$. Survival for the unknown severity groups showed large variations between the regions

TABLE 6. Survival of Those Who Were Alive at Age Two Years by Impairment Variables, Region, and Decade: Percentages Surviving to Ages 10 and 20 Years

\begin{tabular}{|c|c|c|c|c|c|c|c|c|c|c|}
\hline & \multicolumn{4}{|c|}{ 1980s } & \multicolumn{3}{|c|}{$1990 s$} & \multicolumn{3}{|c|}{ Unknown Severity } \\
\hline & $10 \mathrm{y}$ & $20 \mathrm{y}$ & $n$ & SE & $10 \mathrm{y}$ & $n$ & SE & $20 \mathrm{y}$ & $n$ & SE \\
\hline \multicolumn{11}{|c|}{ Severe lower limb function } \\
\hline Mersey & 78 & 58 & 208 & 3.7 & & & & 100 & 1 & \\
\hline North England & 95 & 85 & 55 & 5.1 & 78 & 161 & 3.3 & 65 & 17 & 11.6 \\
\hline North Ireland & 85 & 65 & 158 & 4.2 & 85 & 73 & 4.5 & 88 & 25 & 6.5 \\
\hline Oxford & 83 & 71 & 163 & 4.5 & 93 & 160 & 2.1 & 50 & 6 & 20.4 \\
\hline Scotland & 95 & 80 & 229 & 4.5 & & & & 44 & 25 & 9.9 \\
\hline \multicolumn{11}{|c|}{ Severe upper limb function } \\
\hline Mersey & 74 & 51 & 167 & 4.2 & & & & 100 & 1 & \\
\hline North England & 94 & 80 & 47 & 6.1 & 80 & 157 & 3.5 & 67 & 12 & 13.6 \\
\hline North Ireland & 83 & 58 & 117 & 3.5 & 82 & 47 & 6.0 & 79 & 34 & 7.2 \\
\hline Oxford & 76 & 60 & 104 & 5.8 & 90 & 101 & 3.1 & 50 & 28 & 9.5 \\
\hline Scotland & 92 & 70 & 157 & 6.4 & & & & & & \\
\hline \multicolumn{11}{|c|}{ Severe intellectual impairment } \\
\hline Mersey & 81 & 63 & 228 & 3.4 & & & & 40 & 5 & 21.9 \\
\hline North England & 85 & 70 & 41 & 7.3 & 79 & 143 & 3.6 & 89 & 9 & 10.5 \\
\hline North Ireland & 86 & 68 & 165 & 4.1 & 86 & 64 & 4.6 & 92 & 56 & 4.2 \\
\hline Oxford & 80 & 67 & 128 & 4.9 & 89 & 93 & 3.4 & 90 & 62 & 37.5 \\
\hline \multicolumn{11}{|c|}{ Severe visual impairment } \\
\hline Mersey & 66 & 39 & 74 & 6.5 & & & & 61 & 68 & 6.3 \\
\hline North England & 89 & 61 & 9 & 18.1 & 67 & 32 & 8.7 & 73 & 22 & 9.5 \\
\hline North Ireland & 84 & 60 & 56 & 7.1 & 80 & 27 & 8.3 & 78 & 53 & 5.9 \\
\hline Oxford & 79 & 56 & 62 & 10.1 & 82 & 48 & 6.0 & 79 & 33 & 7.1 \\
\hline Scotland & 90 & 72 & 69 & 5.7 & & & & 92 & 267 & 1.7 \\
\hline
\end{tabular}

$n$ indicates number of cases at beginning of follow-up; SE, standard error at last year of follow-up. For unknown severity, results are for the 1980 s cohort only. 
but also had less precision, reflecting the smaller numbers of cases (Table 6).

\section{Multivariate Survival}

There was a reduction in life expectancy with increasing numbers of multiple severe impairments (Fig 1). Information was available on all 4 impairment variables for 2853 children in all of the regions (excluding Scotland because of poor intellectual impairment data) for both decades. The 475 (17\%) who had either 3 or 4 impairment indicators that were classified as severe accounted for $84 \%$ of the deaths. For children with 2 severe impairments, the proportion who survived to 20 years of age was $>90 \%$, whereas with 4 severe impairments, the proportion who survived to 20 years of age was just $40 \%$. Considering children with all 4 impairment variables recorded as severe, no significant regional variation was observed among the 4 regions. However, once again, Mersey had a slightly poorer outlook and Oxford slightly better (32\% vs $42 \%$ at 20 years).

When a multivariate proportional hazards model was fitted, the best predictors of survival (ie, with the largest estimated relative hazards from age 2 to 20 years between the severe and not severe) were in descending order: severe lower limb impairment (relative hazard: 5.01; 95\% confidence interval [CI]: 2.5-10.1), severe intellectual impairment (relative hazard: 3.91; 95\% CI: 2.3-6.8), severe upper limb impairment (relative hazard: 3.10; 95\% CI: 1.8-5.5), and severe visual impairment (relative hazard: 2.12; 95\% CI: 1.6-2.9).

Furthermore, a significant interaction was found between deprivation status and birth weight: for those who were born in an affluent area, the effect of birth weight was 2.2-fold (95\% CI: 1.2-4.1) that of the effect of birth weight for those who were born in a deprived area (Fig 2). In affluent areas, infants of normal birth weight had an increased relative hazard of 2.0 (95\% CI: 0.8-5.4) compared with those of low birth weight, whereas in deprived areas, infants of normal birth weight had a decreased relative hazard of 0.93 (95\% CI: 0.7-1.3) compared with those of low birth weight. For those who were born in an affluent area with normal birth weight and with all 4 impairment variables recorded as severe, $<30 \%$ survive to 20 years of age, yet for those who were born in affluent areas and had low birth weight and all 4 impairment variables recorded as severe, $>50 \%$ survived to 20 years of age. After the inclusion of these variables in the multivariate model, region or year of birth did not make a significant additional contribution.

\section{DISCUSSION}

\section{Findings}

We have shown that after adjustment for severity of impairment, children who had CP, were born in affluent areas, and had a low birth weight fare much better than children who were born in a similar area had a normal birth weight. However, this result was not replicated (and may even have been reversed) among those who were born in deprived areas. Significant regional variations were evident when the survival by a particular severe impairment variable

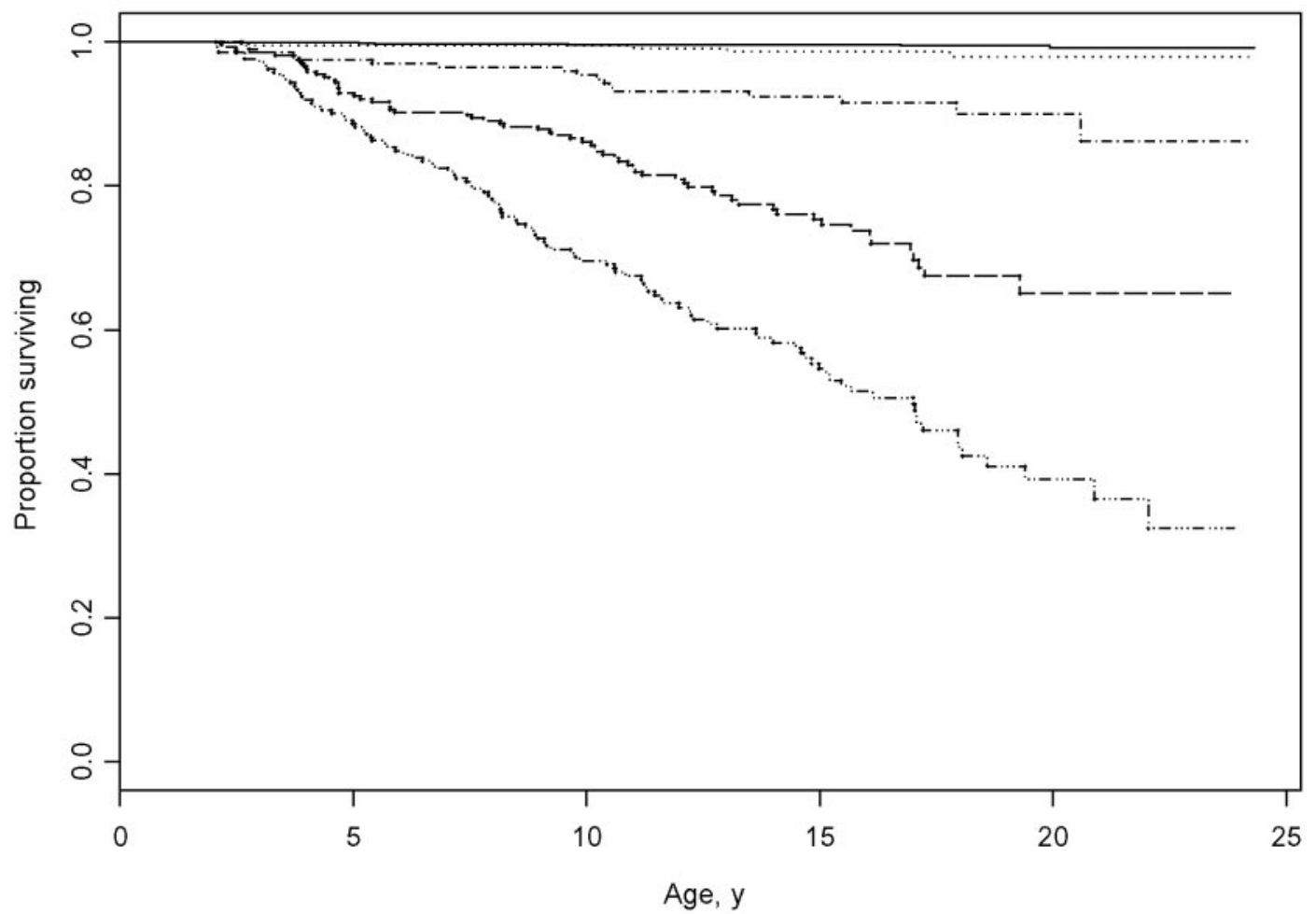

Fig 1. Survival of those who were alive at age 2 years by number of severe impairments for all regions combined: -, no severe impairments, 1843 children with 10 deaths; . . . . . , 1 severe impairment, 341 children with 5 deaths; $-\cdot-, 2$ severe impairments, 194 children with 17 deaths; — - 3 severe impairments, 265 children with 65 deaths; - - - -, 4 severe impairments, 211 children with 105 deaths. 


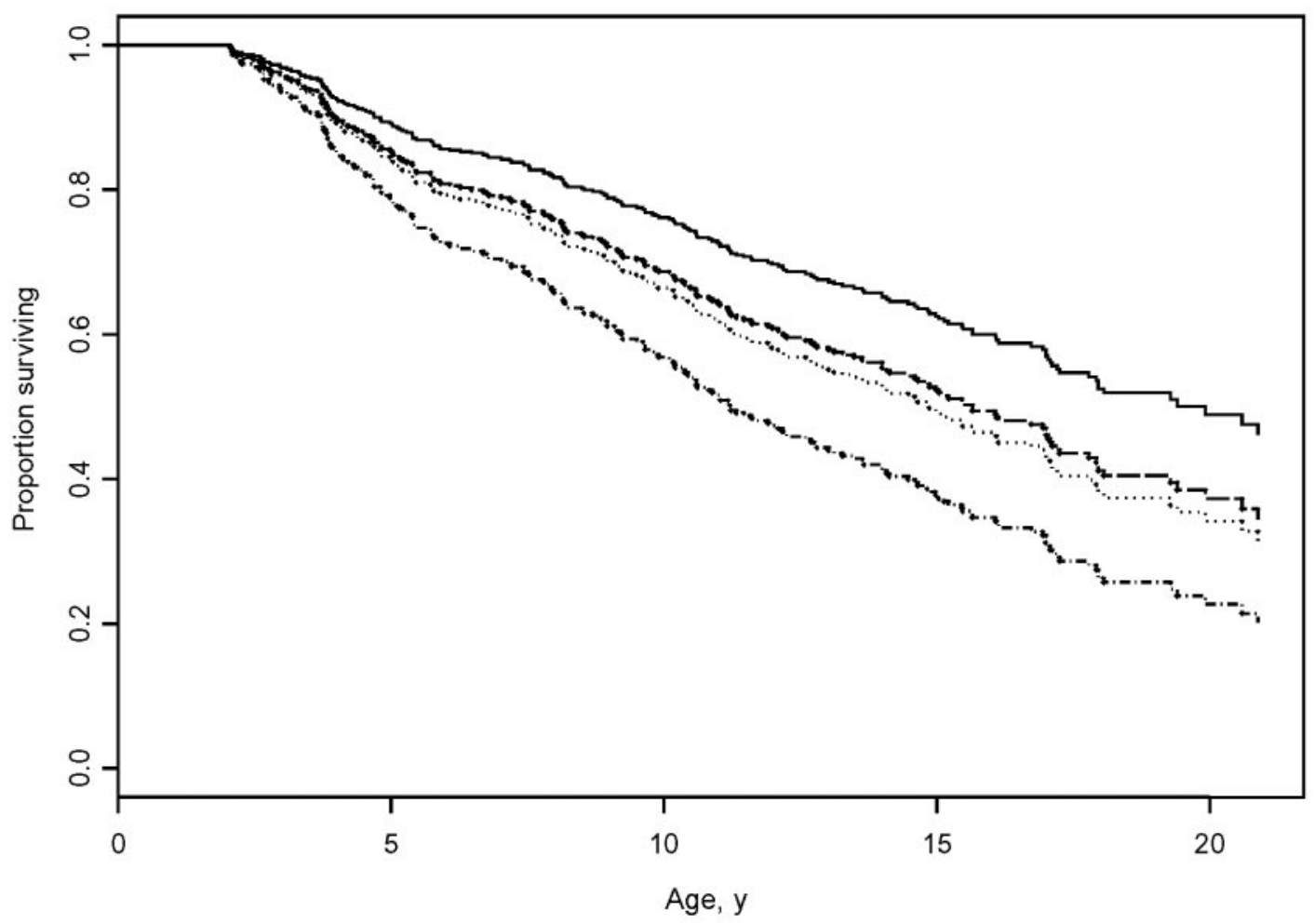

Fig 2. Predicted survival for those who were alive at age 2 years and had 4 severe impairments by birth weight and socioeconomic status, for all regions combined: —, low birth weight and affluent; — - normal birth weight and deprived; $\ldots \ldots$, low birth weight and deprived; $-\cdot-$, normal birth weight and affluent.

was compared. However, no regional variations exist after adjustment for multiple impairments, birth characteristics, and socioeconomic status. Furthermore, within our multivariate analysis over the 2 decades, we found no evidence of any secular changes in survival.

Of those who had 4 severe impairments and were born with normal birth weight and in affluent areas, $<30 \%$ will survive to 20 years of age. This estimate of survival for the most severely impaired group is worse than that previously published ${ }^{9}$ (although within expected margins of error) and is likely to be attributable to the additional contribution that socioeconomic status and birth weight make to survival outlook.

\section{Birth Characteristics}

The survival of those who were born with a low birth weight, contrary to what may be expected, although previously reported, ${ }^{9}$ is better than that of children who were born with a normal birth weight. Infants who are born preterm or with low birth weight are less likely to have severe impairment than those who are born at term or with normal birth weight; even after adjustment for level of impairment, children who are born preterm or with low birth weight still have better survival. ${ }^{9}$ However, our research shows that this holds true only for those who were born to mothers from affluent areas and that little difference is evident between the birth weight groups for those who were born to mothers from deprived areas. Furthermore, for those who were born to mothers from affluent areas, the 2-fold difference in risk reported here between those who were born with a normal birth weight and those who were born with a low birth weight is greater than that previously reported.

Although we have not presented our data on children with late-impairment $C P$ because we know that it is underascertained, it has been shown ${ }^{9}$ that children with late-impairment $\mathrm{CP}$ have a poorer outlook than those with early-impairment $\mathrm{CP}$ for a particular severe impairment. ${ }^{9}$ If one considers gestational age to be a surrogate measure for age at insult and continues this time axis beyond birth to age at insult for late-impairment $\mathrm{CP}$, then it could be hypothesized (again conditioning on severity of impairment) that there is a decrease in life expectancy with increasing age of insult. It would be of additional interest to evaluate influences of socioeconomic status on such outcomes.

\section{Socioeconomic Variations}

All of the UKCP regions except for Oxford happen to cover the more deprived regions of United Kingdom. ${ }^{22}$ A substantial class gradient is known to exist in childhood mortality. Using the National Statistics Socio-Economic Classification, infant mortality rates in the semiroutine and routine laborers (the 2 lowest occupational bands of the National Statistics SocioEconomic Classification) are 5.9 to 6.4 per 1000 live births compared with just 1.8 to 2.5 per 1000 live births in the higher professions. ${ }^{23}$ Perinatal, infant, and childhood mortality also vary by region, much of which might be associated with variations in social class. ${ }^{24,25}$ 
Socioeconomic variations may have wide ranging implications. First, differences in perinatal survival between the socioeconomic groups may affect underlying distributions of $\mathrm{CP}$ between the regions, affecting infants who survive to the age 2 threshold and may be ascertained in a study of this nature. Second, socioeconomic status is related to birth weight (with more infants from lower socioeconomic bands being born with low birth weights). A so-called low birth weight paradox exists where infants who were born with a low birth weight have a lower perinatal mortality when born to women of lower socioeconomic status than a higher socioeconomic status. ${ }^{26}$ However, survival for those children with $\mathrm{CP}$ would suggest a paradox of the normal birth weight infants: children who have $\mathrm{CP}$ and are born with normal birth weight have a lower mortality when born in deprived areas than in affluent areas.

\section{Regional Variation and Data Ascertainment}

Some of the disparity in international comparisons of survival of $\mathrm{CP}$ has been attributed to differences in ascertainment of the very mild and very severe impairment. ${ }^{10}$ Any assessment of regional variation must depend to some extent on assumptions of complete ascertainment or at least equivalent patterns of ascertainment across the regions. Exclusion of children who do not live to age 2 years limits the effect of underascertainment of severe cases. Focusing on those with severe impairment limits the effect of underascertainment of the very mild cases.

An investigation of possible underascertainment using capture-recapture methods in the Oxford region revealed that it was likely that between $13 \%$ and $21 \%$ of cases had not been ascertained across all years of birth and that this rate may be higher in more recent years (A. Silva, $\mathrm{PhD}$, personal communication, 2004). Thus, the observed improvement in survival in the 1990s for Oxford could potentially be confounded by underascertainment issues. However, the estimated degree of underreporting in Oxford was also found to be lower for those with severe impairment compared with those with less severe impairment, and so the improvement in survival observed in those with severe impairment in Oxford in the 1990s may well represent a real improvement.

Ascertainment may also be influenced by whether data were collected retrospectively or prospectively. Retrospective methods may be less likely to ascertain children who had severe impairment and have already died. For instance, a more favorable outlook was observed in the North of England 1980s cohort than the 1990s. The survey initially obtained its cases by retrospective periodic searches, in 1985, 1990, and 1995, and then subsequently by prospective methods.

\section{Implications of Potential Variations in Recording and Definitions}

In an attempt to avoid some of the variation as a result of definition and classification of impairments, we considered only the binary classification of severe or not severe. However, variations in recording of severe impairments may account for some of the variability observed in survival between the regions for those who have severe impairment. In particular, children for whom severity status is unknown may be more likely to have severe impairment than not (eg, because of an inability to test the degree of severity, or the child's dying before testing was conducted). The Mersey register distinguishes between children for whom visual impairment is unknown and those for whom it is impossible to test. The survival for those for whom it is impossible to test is similar to those who have severe impairment. ${ }^{9}$ The North of England register also makes this distinction, but the 3 other registers do not. A detailed statistical analysis (not shown here) showed that such missing data were unlikely to alter the overall conclusions drawn (namely, that there exists regional variation when considering single severe impairments but not when considering multiple severe impairments).

\section{Generalizability}

Large cohorts of children are needed to derive precise estimates of life expectancy for children with $\mathrm{CP}$. A known underreporting of CP on death certificates prevents such information from being taken from routine statistics. This large collaborative study helps to overcome issues of power and small numbers when subgroups of children with CP are studied. The geographically defined populations of each of the registers allows estimates to be applied to total populations.

\section{ACKNOWLEDGMENTS}

Dr Hemming was employed as a research assistant to Professor Hutton and Peter Pharoah under a Medical Research Grant (G9900630) "Life Expectancy in Children and Young Adults With Cerebral Palsy: A UK Collaboration" for the duration of this work. The merging and cleaning of the database was also funded by this grant. The Merseyside and Cheshire register is currently funded by the National Health Services. The North of England Collaborative Cerebral Palsy Survey receives grants from the Directors of Public Health of the Northern and Yorkshire Region and Primary Health Care Trusts. The Four Counties Database of Cerebral Palsy, Vision Loss and Hearing Loss in Children is currently funded by the Department of Health under Research Active Disease Registers. The Scottish Register of Children With Motor Deficit of Central Origin was originally set up in Glasgow University and funded by a grant from the Chief Scientist of the Scottish Office. The register was subsequently transferred to the care of the Information Services Division of National Health Services National Services Scotland. The Northern Ireland Cerebral Palsy register is funded by the Department of Health, Social Services and Public Safety.

We thank each of the members of the UKCP collaboration for providing the data that allowed this work to be undertaken: Professor Pharoah and Deborah Quinney from Mersey; Jackie Parkes and Helen Dolk from Northern Ireland; Ann Johnson, Geraldine Surman, and Jennifer Kurinczuk from Oxford; and Jim Chalmers and Sandra Bonellie from Scotland. The work of coordinating the UKCP collaboration was conducted by Geraldine Surman. The work of merging and cleaning the database was conducted by Andy King, National Perinatal Epidemiology Unit, Oxford. The work of assigning Carstairs scores was conducted by Sam Pattenden, London School of Hygiene and Tropical Medicine. Professor Pharoah (with Professor Hutton) secured funding for this project and helped develop initial ideas. Acknowledgment is given to the National Health Services Central Register for England, the Northern Ireland Central Services Agency, and the General Register Office for Scotland for providing dates of death. 


\section{REFERENCES}

1. Evans PM, Alberman E. Certified cause of death in children and young adults with cerebral palsy. Arch Dis Child. 1990;65:325-329

2. Hutton JL, Cooke T, Pharoah POD. Life expectancy in children with cerebral palsy. BMJ. 1994;309:431-435

3. Crichton JU, Mackinnon M, White CP. Life expectancy of persons with cerebral palsy. Dev Med Child Neurol. 1995;37:567-576

4. Strauss D, Shavelle R, Anderson TW. Life expectancy of children with cerebral palsy. Pediatr Neurol. 1998;18:143-149

5. Strauss D, Shavelle R. Life expectancy of adults with cerebral palsy. Dev Med Child Neurol. 1998;40:369-375

6. Williams K, Alberman E. Survival in cerebral palsy: the role of severity and diagnostic labels. Dev Med Child Neurol. 1998;40:376-379

7. Hutton JL, Colver AF, Mackie PC. Effect of severity of disability on survival in north east England cerebral palsy cohort. Arch Dis Child. 2000;83:468-473

8. Blair E, Watson L, Badawi N, Stanley FJ. Life expectancy among people with cerebral palsy in Western Australia. Dev Med Child Neurol. 2001 43:508-515

9. Hutton JL, Pharoah POD. Effect of cognitive, motor and sensory disabilities on survival in cerebral palsy. Arch Dis Child. 2002;86:84-89

10. Shavelle RM, Strauss DJ, Dey SM. Comparison of survival in cerebral palsy between countries. Dev Med Child Neurol. 2001;43:574

11. Pharoah POD, Platt MJ, Cooke T. The changing epidemiology of cerebral palsy. Arch Dis Child Fetal Neonatal Ed. 1996;75:F169-F173

12. Colver AF, Gibson M, Hey EN, Mackie PC, Richmond S, for the North of England Collaborative Cerebral Palsy Survey. Increasing rates of cerebral palsy across the severity spectrum in north-east England 1964-1993. Arch Dis Child. 2000;83:F7-F12

13. Dolk H, Parkes J, Hill AE. Cerebral palsy prevalence in relation to socioeconomic deprivation in Northern Ireland. Paediatr Perinat Epidemiol. 1996;10:A4
14. Pharoah POD, Cooke T, Johnson MA, King R, Mutch L. Epidemiology of cerebral palsy in England and Scotland, 1984-9. Arch Dis Child Fetal Neonatal Ed. 1998;79:F21-F25

15. Dolk H, Pattenden S, Johnson A. Cerebral palsy, low birthweight and socioeconomic deprivation: inequalities in a major cause of childhood disability. Paediatr Perinat Epidemiol. 2001;15:359-363

16. Mutch L, Ronald E. The Scottish Register of Children With a Motor Deficit of Central Origin 1990-1992. Report to the Office of the Chief Scientist. Edinburgh, Scotland: The Scottish Office; 1992

17. Stanley F, Blair E, Alberman E. Cerebral Palsy Epidemiology and Causal Pathways. London, United Kingdom: Mac Keith Press; 2000:20

18. Morris R, Carstairs V. Which deprivation? A comparison of selected deprivation indices. J Public Health Med. 1991;13:318-326

19. Cox DR, Oakes D. Analysis of Survival Data. London, UK: Chapman and Hall; 1984

20. Therneau TM, Grambsch PM. Modeling Survival Data. New York, NY: Springer; 2000

21. Voutilainen ET, Dickman PW, Hakulinen T. Surv2: software for relative survival analysis, version 2.02b; 1998. Available at: www. cancerregistry.fi/surv2/

22. The English Indices of Deprivation. Rev. London, UK: Office of the Deputy Prime Minister Publications; 2004

23. Vital And Social Statistics: By Local Authority: Regional Trends 38. London, United Kingdom: Office for National Statistics; 2004

24. Woods LM, Rachet B, Riga M, Stone N, Shah A, Coleman MP. Geographical variation in life expectancy at birth in England and Wales is largely explained by deprivation. J Epidemiol Community Health. 2005; 59:115-120

25. Series DH3 No 35: Mortality Statistics: Childhood, Infant and Perinatal. Review of the Register General on Deaths in England and Wales. London, United Kingdom: Office for National Statistics; 2002

26. Gisselmann MD. Education, infant mortality, and low birthweight in Sweden 1973-1990: emergence of the low birthweight paradox. Scan J Public Health. 2005;65:65-71

\section{Books Are Not Perfect}

"Corrections in books are rare. But the conclusion this implies-that books rarely contain errors-is itself incorrect. Books are not usually corrected because they can't be, not because they shouldn't be. [As Seth Mnookin's book "Hard News" shows] putting a statement between hard (or soft) covers does not make it more reliable than one published in a newspaper. ... 'People tend to accept more uncritically what they read in a book than what they read in a magazine or newspaper.' Yet authors themselves, especially the most careful ones, know this mystique is undeserved. Uncorrected errors—some big, some small-are far more common than most publishers admit. ... [F]laws slip through partly because, unlike many magazines and some newspapers, books are not fact-checked in a systematic way. 'Readers imagine that there is a large and complex scholarly apparatus at a publishing house that is verifying the accuracy of what is written.' ... In reality, book publishers do not consider checking facts their responsibility."

Krug N. New York Times. September 25, 2005

Noted by JFL, MD 


\section{Regional Variation in Survival of People With Cerebral Palsy in the United Kingdom}

Karla Hemming, Jane L. Hutton, Allan Colver and Mary-Jane Platt

Pediatrics 2005;116;1383-1390

DOI: 10.1542/peds.2005-0259

This information is current as of December 6, 2005

\begin{tabular}{|ll} 
Updated Information & including high-resolution figures, can be found at: \\
\& Services & http://www.pediatrics.org/cgi/content/full/116/6/1383 \\
References & This article cites 18 articles, 5 of which you can access for free \\
& at: \\
& http://www.pediatrics.org/cgi/content/full/116/6/1383\#BIBL \\
& This article, along with others on similar topics, appears in the \\
following collection(s): & Neurology \& Psychiatry \\
& http://www.pediatrics.org/cgi/collection/neurology_and_psychia \\
& try \\
& Information about reproducing this article in parts (figures, \\
Permissions \& Licensing & tables) or in its entirety can be found online at: \\
& http://www.pediatrics.org/misc/Permissions.shtml \\
& Information about ordering reprints can be found online: \\
Reprints & http://www.pediatrics.org/misc/reprints.shtml
\end{tabular}

\section{American Academy of Pediatrics}

